in quoting my name from a former volume of NATURE in I 872 , as having then announced a cold wave of climate temperature being due to commence in 1878.8 ; or, as he is kind enough to say, the very day on which the severe winter of the years 1878 and 1879 did begin.

I must decline, at all events, the full honous, for these two reasons : firsily, the quoted datum was intended by me to signify the middle, not the beginning, of that cold wave; and as that lasted thirteen months, my date was between six and seven months too soon. Secondly, when I published again on the subject in the Edinburgh Astr. Observations of 1877 , I indicated not 1878.8 , but 1877.8 as the probable date of the then coming, now past, wave of cold, or erred much more than in 1872 .

I have recently been looking into the reason of that latter calamitous failure, and find it clearly enough now on the plates of projections in that volume in this fact-that the then expected minimum of solar spots was inserted for $1877^{\circ}$, or nearly two years sooner than sun observations have since then shown it to be. Rectifying, therefore, now that quantity, and in the then absence of our rock thermometers (which had first indicated the remarkable cycles of temperature in striking connection with the whole period, though not the details, of the sun-spots) using merely air-temperatures and re-drawing the curves, the middle epoch of the late cold wave comes ont $1879^{\circ} \mathrm{I}$, and of the next hot wave $1880^{\circ} 8$.

Now these hot waves, I have always maintained, are more important, more regular, and more directly of solar origin, than the cold waves which are rather due to some indirect earthly effects of watery vapour and its transformations. It may be worth while, therefore, when we are now, as I believe, on the threshold of one of the heat-waves, to mention shortly the data on which the expectation is founded.

These are mainly the actual observations of no less than five occasions of such maxima of temperature occurring in a peculiar kind of dependence on successive sun-spot minima; or rather on the beginning, in each case, of the forces of a new spot cycle. The last such heat.wave was in 1868.8 , or $1 \cdot 8$ year after the then last sun-spot minimum. Next before that in $1857^{\circ} 9$, or $I^{\circ} 9$ years after its previous sun-spot minimum. Before that, in $1846^{\circ}$, or 2.4 years after the same solar test. Before that again, but then depending only on old atmospheric temperature observations, as our rock thermometers were not then existent, in $18344^{\circ}$, or I year after; and still further back, in 1826.5 , or also about I year after the then last sun-spot minimum.

These intervals from one to the other of the hot waves are by no means arithmetically equal, being $1^{*} 9, \mathrm{I}^{\circ} 5, \mathrm{II}^{\circ} 9$, and $8^{\circ} \mathrm{\circ}$. This last (really the earliest of the series) is a frightful inequality, but is borne out, first, by the sun-spot period of that cycle as given by M. Schwabe, having been also anomalously short; and second, by this remarkable testimony, which I have only just become acquainted with, in a ramphlet of most independent character by Sir Robert Christison, Bart., M. D., on tree-growth, read before the Botanical Society in Edinburgh :-

"The wonderful season of 1826 , when warmth and sunshine, commencing with March, ended only with September, and when the summer was continuously such as to change in some respects the habits of the people."

The year 1826 was therefore a crucial case, not only for a maximum of temperature and stnshine in Scotland, but for its keeping such remarkable pace with the then anomalonsly shortened period of sun-spots. While the presently coming case of I 880 will equally prove, by what I have detailed atove, that no certain success in weather predictions for several years beforehand can be hoped for, unless the dates of sun-spot minima can be also anncunced by authority beforehand to a very much smaller quantity than two years of error; and that no mean duration of the sun-spot cycle comes close enough to the fact of the large variations between one cycle and another. We must have therefore each cycle of sun-spots fixed by its own dates alone, and not smoothed away and improved out of creation by being made apparently conformable to others.

I have not yet seen, by those able men who believe they have traced sun-spots to planetary influences of position on the sun, any attempt, from the planetary places in almanacs, to compute the dates of all the solar minima of spots, say from 1825 to 1900. But something of that kind appears now to be necessary for the next steps of the science of the future.

I5, Royal Terrace, Edinburgh, January 9

\section{Cranial Measurements}

IN the notice of my catalogue of crania which you have been good enough to insert in NATURE, vol. xxi. p. 222, your reviewer has given me credit for originality of method, to which I have no wish to lay claim.

I. In reference to the mode of taking the horizontal circum. ference, it is said that I pass "the tape line, not over the prominence of the glabella, as is customary with craniologists, but above it, around the supra-orbital line." The fact is, that the method which I nave adopted, so far from being a deviation from what is customary, is that recommended in the valuable "Instructions Craniologiques," drawn up by Broca and prblished by the French Anthropological Society, and which is used, certainly by the large majority, if not by all the craniologists with whose writings I am acquainted.

2. With regard to the more important measurement of the antero-posterior diameter of the cranium, more important on account of its influence on some of the most characteristic indices, there are, unfortunately, still considerable differences of method, and it was only after very full consideration of the subject that I decided not to follow the French instructions, but to adopt the plan used by Rolleston in "British Barrows," by Barnard Davis in his " Thesaurus Craniorum," and by the majority of German anthropologists. So fully was I convinced of the expediency of the latter, that after having already measured the whole of the crania in the collection, and calculated the indices by the method which included the prominence of the glabella in the cranial length, I took the trouble to remeasure them, with the results given in the catalogue. The object being to obtain, as near as may be, an idea of the form of the brain.case, it appears desirable to exclude all extraneous projections which have no relation to this form. The impossibility of eliminating every source of fallacy, such as those occasioned by the varying thickness of bone or of diploe, is no argument against endeavouring to reduce them, as far as we can, to a minimum. The projection caused by the development of the frontal sinuses should certainly not be omitted in a complete description of a sliull, but it no more affects the form of the cranium proper, than the prominence of the nasal bones or of the maxilla, which, important and instructive as they are from other points of view, are usually ignored in giving what is called the maximum length of the skull, although if the term is to be taken in its literal sense, they have as much claim to be included as the glabella or supra-orbital ridges.

Many other arguments might be adduced and authorities given for the usage I have adopted, but I will bear in mind your request for brevity.

Royal College of Surgeons, January II

"Why the Air at the Equator is not Hotter in January than in July"-Freezing of the Neva

In Nature, vol, xxi. p. I29, Mr. Croll gives his reasons why the equator is not much warmer in January than in July, notwithstanding the greater nearness of the sun at the former season. To state the case briefly, he, having recalled the fact that the whole earth is colder in Jannary than in July, because in the former the cold winter of the northern (or principally land) hemisphere coincides with the mild winter of the southern (or principally water) hemisphere, he continues: "Consequently the air which the equatorial regions receive from the trades must have a higher temperature in Jnly than in January. The northern is the dominant hemisphere ; it pours in hot air in July and cold air in January, and this effect is not counterbalanced by the air from the opposite hemisphere. The mean temperature of the air Fassing into the equatorial regions ought therefore to be much higher in July than in January, and this it no doubt wontd Be were it not for the counteracting effects of eccentricity." And further: "There is another case which must also tend to lower the January and raise the July temperature of the equator: the northern trades pass farther south, and consequertly cool the equatorial regions more during the former than the latter season."

I maintain that there is no such inffuence of the ncrthern trades on the temperature of the equator, because they scarcely anywhere reach it, and then because the lower latitudes of the northern hemisphere are not colder in January than those of the southern hemisphere in July. In the Atlantic the northern trades do not reach the equator at all in Fanuary, but only in February, March, and April, and this but in the western part of the ccean. 